\title{
Dynamic Variations of Cyanobacterial Blooms And Their Response To Urban Development And Climate Change In Lake Chaohu Based On Landsat Observations
}

\author{
Xuemin Qin ( $\nabla$ xueminq@mail.hfut.edu.cn ) \\ Hefei University of Technology https://orcid.org/0000-0003-4137-6488 \\ Wei Xia \\ Hefei University of Technology https://orcid.org/0000-0001-8491-6064 \\ Xiaoxuan Hu \\ Hefei University of Technology
}

Zhen Shao

Hefei University of Technology

\section{Research Article}

Keywords: Cyanobacterial blooms, Urban development, Climate change, Landsat, NDVI, Lake Chaohu

Posted Date: July 23rd, 2021

DOl: https://doi.org/10.21203/rs.3.rs-670667/v1

License: (c) (i) This work is licensed under a Creative Commons Attribution 4.0 International License. Read Full License

Version of Record: A version of this preprint was published at Environmental Science and Pollution Research on January 13th, 2022. See the published version at https://doi.org/10.1007/s11356-02218616-1. 


\section{Abstract}

Recurring cyanobacterial blooms have seriously hindered the sustainable development of cities. In this study, the variation trend of cyanobacterial blooms was analyzed by taking Lake Chaohu in China as the study area, and the Normalized Difference Vegetation Index (NDVI) derived from Landsat observations combined with the development index of surrounding cities from 2009 to 2019 was used to quantitatively analyze the response of cyanobacterial blooms to urban development and climate change. The results showed that the NDVI of the Northwest Lake region was significantly higher than that of other regions. Summer and autumn were the main seasons for the outbreak of cyanobacterial blooms. The NDVI of Lake Chaohu and Baohe Lake region showed a significant correlation with the gross domestic product (GDP) growth rate of Hefei city (HF), the districts and counties around the lake (DCL)هBaohe District (BH) and the population $(\mathrm{P})$. As the economic regions gradually focused on $\mathrm{BH}$ rather than on $\mathrm{HF}$ and $\mathrm{DCL}$, there was an increasing trend correlation between the NDVI of Baohe Lake region and the GDP growth rate. However, the elimination of GDP in BH did not affect the consistency relationship between the economic growth of other regions and the NDVI of Lake Chaohu on a large scale. In addition, the results of relative importance analysis indicated that the GDP growth rate of $\mathrm{BH}$ and the area of Hefei except DCL (HF-DCL) accounted for important contribution to the $R^{2}$ of the regression. This study has momentous reference value for understanding the coupling relationship between urban development and lake environment.

\section{Introduction}

With the acceleration in the development process of industrial and agricultural modernization and urbanization, human activities have intensified the eutrophication of lakes in surrounding cities, leading to the frequent occurrence of cyanobacterial blooms (Deng et al., 2016; Zhang et al., 2018). At present, algal blooms have become one of the most serious and challenging ecological environmental problems (Huisman et al., 2018). Numerous large lakes around the world have seen severe cyanobacterial blooms, such as Lake Taihu (Qin et al., 2015) and Lake Chaohu in China (Shi et al., 2013) and Winnipeg Lake in Canada (Schindler et al., 2012). Frequent cyanobacterial blooms not only worsen the sensory properties of water bodies but also damage the overall balance of the lake ecosystem and have a serious impact on human health, residential life, and economic development (Shi et al., 2017; Zhou et al., 2008). According to the environmental consensus, there is a strong link between the frequent occurrence of cyanobacterial blooms and the economic process, population growth, and industrial and agricultural production of surrounding cities (Deng et al., 2016; Paerl et al., 2014). Nevertheless, there is still a lack of quantitative research on the correlation between them, which mainly stems from the neglect of the cumulative effect on the development of cyanobacteria in the advancement process of urbanization. Therefore, studying the response of cyanobacterial blooms to urban development and climate change can advance the research paradigm of cyanobacteria influencing factors, effectively predict the growth trend of cyanobacterial bloom, optimize the spatial development pattern between cities and lakes, and provide an 
important decision-making basis for the sustainable development of urban planning and industrial layout.

The formation and evolution of cyanobacterial blooms are affected by human activities, the climate, the environment, and other factors. The interaction among these factors results in the complex temporal and spatial variation of cyanobacterial blooms. Previous studies focused on the trend variation of cyanobacteria caused by meteorological and environmental factors. Specifically, Huang et al. (2020) used the general regression neural network model to determine the complex relationship between harmful algal blooms and environmental factors and revealed the regional magnitude of harmful algal blooms and related driving factors. Walls et al. (2018) found that when the temperature was higher than $18^{\circ} \mathrm{C}$, the rise of water temperature would promote the growth of cyanobacteria. However, changes in the form and scale of human activities can also significantly affect the growth of cyanobacteria. Under the background of huge social and economic changes, it is essential to study the dynamics of cyanobacterial blooms in surrounding lakes and their response to population aggregation and socioeconomic development. Generally, the interaction between natural and anthropogenic factors significantly influences lake changes. However, the impact of human factors is weakened by the prominent effect of natural factors and the lagging and long-term influence of anthropogenic factors. These factors can be studied from the perspective of determining how cyanobacteria respond to human activities and climate factors with different intensities. Thus, it is necessary to select typical cases with significant variation caused by urban development to study the dynamic rules of cyanobacterial blooms.

We chose the research objects based on the measurement criteria of the development speed of urban economy and the change of the distance between cities and lakes. There are 27 lakes in China with a surface area larger than $500 \mathrm{~km}^{2}$ (Ma et al., 2010). As a typical central lake, Lake Chaohu, located in the middle of Anhui Province, is the primary source of drinking water for Hefei city (HF) and Chaohu city (Qin et al., 2013). It has an important geographical location and ecological strategic position. In recent years, the construction of Binhu New District, which belongs to Baohe District $(\mathrm{BH})$, has gradually shortened the distance between Lake Chaohu and Hefei, making Hefei a real lakeside city. Moreover, Hefei city, with one of the fastest rates of economic growth in the world in recent decades, has had a significant effect on Lake Chaohu. Taking Lake Chaohu and the economic belt around Lake Chaohu as the sample, we analyzed the response of cyanobacterial blooms in Lake Chaohu to urban expansion, economic growth, population aggregation, and climate change from a multi-dimensional perspective, which is conducive to revealing the relationship between water pollution and urban development and providing support for the optimization and adjustment of industrial structure and spatial layout.

Field sampling and laboratory measurements are the main conventional methods to obtain information on cyanobacteria (Oyama et al., 2015). However, field sampling can only be used for local surveys, with limited sampling frequency, high cost, and increased time, and when the spatial and temporal scale is large, it is finite to disclose the information of cyanobacterial blooms (Kutser, 2004; Wang et al., 2011). At present, 12 monitoring sites are employed to observe the cyanobacteria in Lake Chaohu. However, because of the limited sampling sites and short time span, the data have low spatial and temporal 
resolutions. In addition, we need to extract information from the entire lake to reveal the long-term response of cyanobacteria dynamics to urban development and climate change on a broader spatial scale. Satellite remote sensing technology can provide multi-temporal, multi-scale, and multi-spectral observation information of cyanobacterial blooms in the same area, which can quickly, effectively, and dynamically reflect its spatiotemporal characteristics through the analysis and processing of remote sensing image data (Vincent et al., 2004; Wu et al., 2016). This tool can compensate for the limitations of traditional monitoring methods and has become an essential technical means for dynamic monitoring of the water environment, providing valid spatiotemporal resolution for monitoring variation in inland, coastal waters, and various ecosystem (Hu et al., 2010; Mu et al., 2020; Palmer et al., 2015).

The Normalized Difference Vegetation Index (NDVI) is obtained by a nonlinear combination of the nearinfrared band and the red band from remote sensing images (Jarchow et al., 2017). Because the spectral characteristics of the outbreak area of cyanobacterial blooms are similar to that of green vegetation (Zhu et al., 2010), the NDVI can be used as an effective index to extract the information on cyanobacterial blooms. Recently, the NDVI has been successfully applied to explore the temporal and spatial dynamics of algae. Kiage and Walker (2009) used the NDVI to monitor duckweed and floating vegetation in Lake Maracaibo, Venezuela and confirmed the tremendous potential of the NDVI in monitoring floating vegetation. Ma et al. (2021) employed the NDVI method to extract information on harmful algal blooms in Lake Chaohu, with an accuracy of $96.1 \%$. Vijay et al. (2016) defined the NDVI as an index of algae density and assessed the correlation between the NDVI and Normalized Difference Water Index (NDWI). In a word, the NDVI can effectively reflect the information on cyanobacteria in lakes and can combine cyanobacteria dynamics, human activities, and climate changes for research.

This study focused on the dynamic variations of cyanobacterial bloom and their response to urban development and climate change in Lake Chaohu. The main contributions of this study are as follows: first, we observed the ecological environment of cyanobacterial blooms in lake from the perspectives of economic growth, population aggregation, and climate change, which advances the knowledge development of the complex interaction among the influencing factors of cyanobacteria. Second, taking Lake Chaohu as a typical case, we aimed to reveal the annual and seasonal spatiotemporal variations of cyanobacterial blooms and to verify the significant impact of different factors on cyanobacteria by constructing a statistical analysis framework integrating remote sensing data, socio-economic data, and meteorological data. Third, we determined the response level of cyanobacterial blooms in Lake Chaohu and the Baohe Lake region to economic growth in different regions by considering the difference in economic growth in different areas. In general, the analysis results of cyanobacterial bloom variation trend with urban development provide useful insights for optimizing the industrial pattern and urban layout in this region and for strengthening the cognition of the coupling relationship between urban development and the lake environment.

\section{Materials And Methods}

\subsection{Study area}


As the fifth-largest freshwater lake in China, Lake Chaohu is a shallow lake located in the middle of Anhui Province and on the left bank of the lower reaches of the Yangtze River floodplain, with a total area of about $780 \mathrm{~km}^{2}\left(31^{\circ} 25^{\prime}-31^{\circ} 43^{\prime} \mathrm{N}\right.$ and $\left.117^{\circ} 17^{\prime}-117^{\circ} 51^{\prime} \mathrm{E}\right)$ (Fig. 1), and it has a subtropical monsoon climate (Jiang et al., 2014; Tang et al., 2015; Xue et al., 2017). It has a mean water depth of $3.1 \mathrm{~m}$, a maximum water depth of $7.7 \mathrm{~m}$, an annual mean temperature of the whole basin of $15^{\circ} \mathrm{C}-16^{\circ} \mathrm{C}$, and an annual mean rainfall of $1100 \mathrm{~mm}$ (Chen et al., 2013). A total of 33 rivers with different levels of pollution flow into Lake Chaohu (Jiang et al., 2014), including eight major inflowing rivers, accounting for more than $80 \%$ of the total runoff volume in the catchment area. The Yuxi River, an outflowing river, has the only channel that connects with Lake Chaohu and empties into the Yangtze River (Xue et al., 2017).

Lake Chaohu is adjacent to Hefei (the capital of Anhui Province) and Chaohu, which are the two cities that had a permanent population of 8.19 million and 0.8 million, respectively, in 2019. The pollutants produced by economic development and population aggregation are mainly transported to Lake Chaohu through river runoff (Wang et al., 2013), causing serious pollution and eutrophication problems (Zan et al., 2011). Therefore, Lake Chaohu has become one of the most eutrophic lakes in China (Yin et al., 2011). According to the "Bulletin on China's Ecological Environment in 2019," issued by National Environmental Protection Agency, Lake Chaohu was generally in a state of mild eutrophication in 2019. As one of the "Three Rivers and Three Lakes" under the state's key governance, it still plays an important role in people's lives and the economic development around the surrounding cities.

\subsection{Data sources and preprocessing}

\subsubsection{Landsat data acquisition and processing}

To objectively reveal the temporal and spatial distribution characteristics of cyanobacterial blooms, Landsat 7-8 remote sensing images with a time span of 11 years (2009-2019) were downloaded from the official United States Geological Survey website (https://earthexplorer.usgs.gov). Landsat 7-8 satellites carry the Enhanced Thematic Mapper (ETM+) and Operational Land Imager (OLI) sensors, respectively. Both of them have a 30-m spatial resolution, which is the highest resolution image that can be openly obtained to monitor the cyanobacteria currently, with high revisit frequency and reliability. OLI includes all the bands of ETM + sensors, and to improve the data quality and avoid atmospheric absorption characteristics, the bands are re-adjusted to better distinguish different features of ground objects (Pahlevan et al., 2014). To avoid the deviation caused by cloud cover, a total of 69 cloudless Landsat 7-8 remote sensing images above Lake Chaohu were selected to identify and extract cyanobacteria information, and these were sufficient for this study. Each remote sensing image contained two adjacent paths (path 121, row 38), which were orthorectified and geometrically corrected. All images data were preprocessed by ENVI 5.3 software, including converting the digital number(DN) value of the original record into top-of-atmosphere (TOA) radiation according to the radiometric calibration coefficient provided in the metadata file (Chander et al., 2009) and then using the FLAASH (Fast Line-of-sight 
Atmospheric Analysis of Spectral Hypercube) module to generate atmospherically corrected surface reflectance (Nazeer et al., 2014).

\subsubsection{Socioeconomic dataset}

Lake Chaohu is surrounded by Baohe District, Chaohu city, Feidong County, Feixi County and Lujiang County in the city of Hefei, being called the districts and counties around the lake (DCL). The remaining areas are referred to as the area of Hefei except DCL (HF-DCL). The main urban area of Hefei is directly adjacent to the western part of Lake Chaohu. In recent years, the development of the main urban area accounted for the primary economic growth of Hefei and brought in a large population. Thus, with the rapid development of the cities around the lake, the outbreak degree of cyanobacterial blooms in Lake Chaohu shows the characteristics of the spatiotemporal distribution in the western part, which is obviously more severe than that in the middle and eastern part. In this study, the gross domestic product (GDP), a general index to measure the development level, was used to express the urbanization level of the basin and also to consider population aggregation so as to measure the intensity of human activities in this region (Du and Sun, 2017; Guan et al., 2014). The GDP, industry value, and population data of DCL and Hefei from 2009 to 2019 were collected from Anhui Provincial Bureau of Statistics (http://tjj.ah.gov.cn/), as shown in Table 1, to explore the influence of socioeconomic factors on the temporal and spatial distribution of cyanobacterial blooms in Lake Chaohu.

Table 1 Socioeconomic data from 2009-2019 year used in this study ${ }^{a}$

\begin{tabular}{|llll|}
\hline Category & Parameters & Abbreviation & Unit \\
\hline Socioeconomic factors & Gross Domestic Product & GDP & billion RMB \\
\cline { 2 - 4 } & Primary industry & PI & billion RMB \\
\cline { 2 - 4 } & Secondary industry & SI & billion RMB \\
\hline Tertiary industry & TI & billion RMB \\
\hline Population & $\mathrm{P}$ & million \\
\hline
\end{tabular}

aSocioeconomic factors included industry value and population. "Parameters" represent the impact factors obtained by the specific refinement of the two types of factors of industry value and population. The use of each factor in this study was in the form of the abbreviations defined in the table. The value of each industry and population is given in billion RMB and million, respectively.

\subsubsection{Meteorological dataset}

Meteorological data factors, including daily wind speed $(\mathrm{m} / \mathrm{s})$, temperature $\left({ }^{\circ} \mathrm{C}\right)$, precipitation $(\mathrm{mm})$, and sunshine (h) data from 2009 to 2019 , were obtained from the Hefei meteorological station $\left(31^{\circ} 47^{\prime} \mathrm{N}\right.$, $117^{\circ} 18^{\prime} \mathrm{E}$ ), with the station number 58321 , which is the nearest national station to Lake Chaohu (Zhang et al., 2015). The data were downloaded from the China Meteorological Data Sharing Service System 
(http://cdc.nmic.cn) and are presented in Table 2. Meteorological station data were used to analyze the main meteorological drivers of cyanobacterial blooms.

Table 2 Meteorological data from 2009-2019 year used in this study ${ }^{b}$

\begin{tabular}{|lllll|}
\hline Category & & Parameters & Abbreviation & Unit \\
\hline \multirow{3}{*}{ Meteorological factors } & Wind speed & Average wind speed & AWS & $\mathrm{m} / \mathrm{s}$ \\
\cline { 3 - 5 } & & Maximum wind speed & MWS & $\mathrm{m} / \mathrm{s}$ \\
\cline { 3 - 5 } & Extreme wind speed & EWS & $\mathrm{m} / \mathrm{s}$ \\
\hline Temperature & Average temperature & AT & ${ }^{\circ} \mathrm{C}$ \\
\cline { 2 - 5 } & Maximum temperature & MaxT & ${ }^{\circ} \mathrm{C}$ \\
\cline { 2 - 5 } & Minimum temperature & MinT & ${ }^{\circ} \mathrm{C}$ \\
\hline Sunshine & Sunshine hours & $\mathrm{SH}$ & $\mathrm{h}$ \\
\hline Precipitation & $20-20$ h precipitation & $\mathrm{HP}$ & $\mathrm{mm}$ \\
\hline
\end{tabular}

bMeteorological factors included wind speed, temperature, precipitation, sunshine. "Parameters" represent the impact factors obtained by the specific refinement of the four types of factors. The use of each factor in this study was in the form of the abbreviations defined in the table. Wind speed, temperature, precipitation, and sunshine are given in $\mathrm{m} / \mathrm{s},{ }^{\circ} \mathrm{C}, \mathrm{mm}$, and $\mathrm{h}$, respectively.

\subsection{Methods}

\subsubsection{NDVI derivation from Landsat images}

In 1978, Deering first proposed that the simple Ratio Vegetation Index (RVI) was nonlinearly normalized to obtain the NDVI, and the ratio was limited between -1 and 1 (Deering, 1978). At present, the NDVI has become the most widely used vegetation index and can be used as an efficient indicator of the presence of cyanobacteria on the lake surface (Ma et al., 2021). In this study, the NDVI was defined as the normalized ratio of the spectral reflectance of the red band and the near-infrared band and is given by

$N D V I=\frac{\rho_{\text {NIR }}-\rho_{R}}{\rho_{\text {NIR }}+\rho_{R}}$,

where $p_{R}$ and $p_{N R}$ are the reflectance of the red band and the near-infrared band, respectively; $R$ represents band 3 (0.63-0.69 um) of the Landsat 7 image and band 4 (0.64-0.67 um) of the Landsat 8 image; and NIR represents band $4(0.76-0.90 \mathrm{um})$ of the Landsat 7 image and band $5(0.85-0.88 \mathrm{um})$ of the Landsat 8 image. Positive values indicate vegetation coverage, which increase with the enlargement of coverage; negative values indicate that the ground cover is cloud, water, or snow, which has high reflectance to the red band; zero values represent rock or bare soil; and NIR and are approximately equal (Ma et al., 2007; Stow et al., 2003). To further minimize the interference of cloud cover and atmosphere in 
the data, the maximum value composites (MVC) technique was used to maximize the NDVI of each pixel from daily images to obtain the monthly data, and the monthly data were further processed to obtain the annual maximum NDVI data (Telesca and Lasaponara, 2005). To highlight the effect of the NDVI, the NDVI values used in our study were expanded by 1000 times on the original basis.

\subsubsection{Pearson correlation analysis}

To analyze the relationship between cyanobacteria coverage variations and climate factors, the Pearson correlation method was used to calculate the correlation coefficients between annual and seasonal coverage and meteorological factors, and the significance $t$-test was carried out. Finally, the $t$-distribution was used to determine the significance level of correlation. By comparing the effects of different meteorological factors on the annual and seasonal cyanobacteria coverage in Lake Chaohu, we could explain the correlation between the interannual and seasonal variations of the NDVI and the spatiotemporal variations of climate variables. The statistical analysis was performed by Statistical Program for Social Sciences (SPSS 20.0) software (version 20.0).

$$
\begin{aligned}
& r=\frac{\sum_{i=1}^{N}\left(x_{i}-\bar{x}\right)\left(y_{i}-\bar{y}\right)}{\sqrt{\sum_{i=1}^{N}\left(x_{i}-\bar{x}\right)^{2} \sum_{i=1}^{N}\left(y_{i}-\bar{y}\right)^{2}}} \\
& t=\frac{r}{\sqrt{\left(1-r^{2}\right) /(n-2)}}, d f=n-1,
\end{aligned}
$$

where $x_{\mathrm{i}}$ and $y_{\mathrm{i}}$ are the area percentage of the NDVI at different levels and the meteorological element value in the ith year or season, respectively; $N$ is the number of statistical years or seasons; $\overline{\mathrm{x}}$ represents the average NDVI area percentage corresponding to different levels of statistical years or seasons; $\forall y$ denotes the average value of meteorological elements during the statistical years or seasons; and $t$ and $d f$ are the test statistic and degree of freedom, respectively.

Additionally, the trend relationship between socioeconomic factors and the annual average NDVI in Lake Chaohu and Baohe Lake region was analyzed based on the simple linear regression and multiple linear regression methods. Relative Importance (RI) analysis was also used to determine the relative effects of economic growth in different regions on cyanobacterial blooms.

\section{Results}

\subsection{Annual spatiotemporal variations}

The annual NDVI variations of Lake Chaohu from 2009 to 2019 were obtained by using MVC technique to calculate the annual maximum value of each pixel from the total number of images in a given year. As shown in Fig. 2, Lake Chaohu was in a state of mild eutrophication during the study period, and the annual maximum NDVI value appeared in 2012, when it was 0.92. Interannual variation in the NDVI showed an upward trend from southeast to northwest, and the outbreak degree of cyanobacterial blooms in 2009-2014 was more serious than that in 2015-2019, mainly because of the rapid development of 
the Binhu New District and the discharge of domestic pollutants, which resulted in the high incidence of cyanobacterial blooms in the Northwest Lake region.

The annual maximum NDVI was divided into three intervals to efficiently explain the outbreak of cyanobacterial bloom in Lake Chaohu from 2009 to 2019. We chose NDVI thresholds of 0.1 and 0.3 for classification statistics (Cao and Han, 2021; Ma et al., 2007). NDVI values less than 0.1 indicate noncyanobacteria, NDVI values between 0.1 and 0.3 indicate a mixture of cyanobacteria and water, and NDVI values greater than 0.3 represent cyanobacteria. Figure 3 shows that the proportion of NDVI values in the range of $0.1-0.3$ and over 0.3 in 2010 was $19.18 \%$ and $21.08 \%$, respectively, which was the highest in the whole study period. From 2010 to 2017, the ratio of NDVI values between 0.1 and 0.3 and greater than 0.3 showed a gradually decreasing trend in general. The proportion of NDVI values in the range of $0.1-0.3$ and over 0.3 reached $8.35 \%$ and $13.29 \%$, respectively, showing a significant increase in 2018 .

\subsection{Seasonal spatiotemporal variations}

In this study, the astronomical season division method was used to divide the four seasons, that is, March to May is spring, June to August is summer, September to November is autumn, and December to the following February is winter. The seasonal variation in the NDVI was obtained by calculating the maximum NDVI value for each pixel of all Landsat images from that season. According to Figs. 4 and 5 , there were significant differences among the different seasons in Lake Chaohu. Cyanobacterial blooms mainly occurred in summer and autumn, especially in autumn. The area of Lake Chaohu with NDVI not less than 0.1 accounted for $4.31 \%, 22.40 \%, 67.87 \%$ and $8.98 \%$ in spring, summer, autumn, and winter, respectively. The highest NDVI occurred in September to November (autumn), during which the percentage of NDVI values from 0.1 to 0.3 and over 0.3 was $22.42 \%$ and $45.45 \%$, respectively.

\subsection{Meteorological driving factors for NDVI dynamics}

To demonstrate the driving influence of meteorological factors on the variation of the NDVI in Lake Chaohu, we collected eight meteorological factors from four categories: temperature $(T)$, wind speed (WS), precipitation (HP), and sunshine (SH). The data time-span was consistent with that of the remote sensing data acquisition time. The monthly data were obtained from the average of daily temperature and wind speed and the accumulation of sunshine hours and precipitation, as shown in Fig. 6. Lake Chaohu had a range of temperatures from $-3^{\circ} \mathrm{C}$ to $35.8^{\circ} \mathrm{C}$, and strong winds, with an AWS value of $3.03 \mathrm{~m} / \mathrm{s}$. It also had average precipitation and sunshine hours of $91.43 \mathrm{~mm}$ and $148.55 \mathrm{~h}$, respectively.

We applied Pearson correlation analysis to explain the relationship between the NDVI and meteorological factors. As shown in Table 3, the coverage variation of the NDVI in Lake Chaohu is significantly related to sunshine, temperature and wind speed $(P<0.05)$. Among them, the ratio of NDVI values less than 0.1 had a positive correlation with EWS $(r=0.621, P<0.05)$. The proportion of NDVI values from 0.1 to 0.3 was positively correlated with SH $(r=0.433, P<0.05)$ and had negative relationship with EWS $(r=-0.617, P<$ 0.05). In addition, there was a positive correlation between the percentage of NDVI values over 0.3 and AT $(r=0.653, P<0.05)$. 
Table 3 Pearson correlation coefficient between NDVI area percentage at different levels and meteorological factors in Lake Chaohu

\begin{tabular}{|c|c|c|c|c|c|c|c|c|}
\hline \multirow{2}{*}{$\begin{array}{l}\text { Influence } \\
\text { factors }\end{array}$} & \multirow{2}{*}{$\begin{array}{l}\text { Precipitation } \\
\text { HP }\end{array}$} & \multirow{2}{*}{$\begin{array}{l}\text { Sunshine } \\
\mathrm{SH}\end{array}$} & \multicolumn{3}{|c|}{ Temperature } & \multicolumn{3}{|c|}{ Wind speed } \\
\hline & & & AT & MaxT & MinT & AWS & MWS & EWS \\
\hline $\mathrm{NDVI}<0.1$ & -0.145 & -0.411 & $\overline{0} .600$ & $\overline{0} .322$ & 0.106 & $\overline{0} .434$ & $\overline{0} .259$ & $0.621^{*}$ \\
\hline NDVI $0.1-0.3$ & 0.125 & $0.433^{\star}$ & 0.506 & 0.236 & $\overline{0} .150$ & 0.461 & 0.306 & $\overline{0.617 *}$ \\
\hline$N D V I>0.3$ & 0.155 & 0.409 & $0.653^{*}$ & 0.382 & $\overline{0} .061$ & 0.388 & 0.205 & $\overline{0} .595$ \\
\hline
\end{tabular}

** denotes a significance level of $1 \%$; * denotes a significance level of $5 \%$

Furthermore, we conducted the correlation analysis between the seasonal NDVI and meteorological factors to demonstrate the seasonal variation between meteorological factors and cyanobacteria coverage. As shown in Table 4, the seasonal NDVI variations had a significant relationship with precipitation $(P<0.05)$, sunshine $(P<0.05)$, and wind speed $(P<0.01)$. The proportion of seasonal NDVI values less than 0.1 was negatively correlated with seasonal HP $(r=-0.290, P<0.05)$ and positively correlated with seasonal AWS $(r=0.722, P<0.01)$. Moreover, the ratio of seasonal NDVI values from 0.1 to 0.3 had a positive correlation with seasonal SH $(r=0.347, P<0.05)$, and both seasonal AWS and seasonal MWS had a negative relationship $(r=-0.706, P<0.05 ; r=-0.660, P<0.05)$. Furthermore, there was a negative correlation between the percentage of NDVI values over 0.3 and seasonal EWS $(r=-$ $0.588, P<0.05)$.

Table 4 Pearson correlation coefficient between seasonal NDVI area percentage at different levels and meteorological factors in Lake Chaohu 


\begin{tabular}{|lllll|}
\hline Influencing factors & & Seasonal & Seasonal & Seasonal \\
& & NDVI $<0.1$ & NDVI 0.1-0.3 & NDVI >0.3 \\
\hline Seasonal precipitation & seasonal HP & $-0.290^{*}$ & 0.355 & 0.250 \\
\hline Seasonal sunshine & seasonal SH & -0.287 & $0.347^{*}$ & 0.249 \\
\hline Seasonal temperature & seasonal AT & -0.302 & 0.371 & 0.258 \\
\cline { 2 - 5 } & seasonal MaxT & 0.137 & -0.105 & -0.154 \\
\cline { 2 - 5 } & seasonal MinT & 0.018 & 0.080 & -0.076 \\
\hline Seasonal wind speed & seasonal AWS & $0.722^{\star *}$ & $-0.706^{*}$ & -0.725 \\
\cline { 2 - 5 } & seasonal MWS & 0.683 & $-0.660^{*}$ & -0.691 \\
\cline { 2 - 5 } & seasonal EWS & 0.578 & -0.552 & $-0.588^{\star}$ \\
\cline { 2 - 5 }
\end{tabular}

** denotes a significance level of $1 \%$; * denotes a significance level of $5 \%$

\subsection{Socioeconomic driving factors of NDVI dynamics}

During the 11-years study period, the population and GDP of Hefei increased from the original 5.1 million and 210.21 billion RMB to 8.19 million and 940.94 billion RMB, respectively, in 2019 (Fig. 7a). The rapid economic development and population accumulation accelerated the rates of eutrophication in Lake Chaohu. This study revealed the driving relationship between the development of neighboring cities and water body by the correlation between GDP growth rate, population and the NDVI.

The annual average NDVI value of Lake Chaohu from 2009 to 2019 ranged from 1.94 to 25.7 , with an average value of 11.5. The highest value appeared in 2011; then, the NDVI declined, hitting the lowest value in 2016 (Fig. 7b). The reason why the lowest value was obviously lower than that of other years may be due to the lag of the comprehensive treatment effect of the lake water environment. The GDP growth rate series of HF, DCL and BH had the same trend correlation with the annual average NDVI time series (Fig. 8a, C, e). With the narrowing of the economic region, the $R^{2}$ decreased from 0.64 to 0.53 , and the linear relationship between the growth rate of Hefei, excluding the GDP of Baohe District, and the annual average NDVI of Lake Chaohu did not change significantly (Fig. 8f). This is because Lake Chaohu bears the environmental pressure exerted by the whole Hefei and not just the surrounding areas. The reason may also be that the economic growth of Baohe District leads to frequent outbreaks of cyanobacterial bloom in the lake region, but the impact of Baohe Lake region is weakened when considering the NDVI of the entire lake. Additionally, the population difference of Hefei, the population of DCL, and the annual average NDVI time series also maintained a certain trend of consistent variation $\left(R^{2}=0.47, P<0.05 ; R^{2}=0.35, P<0.05\right)($ Fig. 8b, d).

To explore the response of cyanobacterial bloom to the growth of GDP and population in Baohe District, we accessed the Baohe Lake region based on the remote sensing image cropping of Lake Chaohu and 
extracted NDVI characteristics from 2009 to 2019. The range of variation was from 1.85 to 83.90, with an average value of 27.14 (Fig. 9a). In 2018 and 2019, the NDVI value showed an abnormal increase and decrease, respectively, which may have occurred due to the unusual climate and the several algae-water separation stations that came into use.

In general, the GDP growth rate series of $\mathrm{HF}, \mathrm{DCL}$, and $\mathrm{BH}$ had consistent variations with the annual average NDVI time series of Baohe Lake region (Fig. 9b, c, d). In particular, the GDP growth rate of HF had almost the same trend correlation with the NDVI time series of the Baohe Lake region $\left(R^{2}=0.93, P<\right.$ 0.005). The results showed that the annual average NDVI of the Baohe Lake region was more related to the rapid economic development in the Baohe District and the environmental pressure increases in the northwest coastal waters of Lake Chaohu which led to the frequent occurrence of cyanobacterial blooms.

Moreover, we also found the variation trend of the growth rate of the secondary industry in the Baohe District and the annual average NDVI of the Lake region. There was a significant positive correlation between the two parameters $(r=0.879, P<0.01)$, with a higher linear fitting degree $\left(R^{2}=0.77, P<0.005\right)$ (Fig. 9E), indicating that the industrial development of Baohe district promoted the outbreak of cyanobacterial blooms. In addition, the total population of DCL was also synchronized with the annual average NDVI time series of the Baohe Lake region $\left(R^{2}=0.28, P<0.05\right)$ (Fig. 9F).

The economic growth of $\mathrm{BH}, \mathrm{DCL}$, and HF had a significant impact on the NDVI of Lake Chaohu and Baohe Lake region. Nevertheless, under this influence, will economic growth in different regions have the same effect on cyanobacterial blooms in Lake Chaohu? We explored and quantified the differences in the impact of economic growth in different regions on cyanobacterial blooms, which will be beneficial for the sustainable development of Lake Chaohu's environment and regional economy and for adjusting decision-making on urban regional planning.

Since the construction of the Binhu New District, the distance between Baohe District and Lake Chaohu has been constantly shortened, and the economy has developed rapidly. Furthermore, there is almost the same trend correlation between the GDP growth rate of Baohe District and the NDVI value of the Baohe Lake region, and whether the eonomic growth of different areas has difference in influencing the NDVI value in Lake Chaohu is still a problem that needs to be studied. Consequently, when considering the effect of the economic growth of DCL, Baohe District should be taken as a separate object of consideration. The remaining area is considered as the area of DCL except Baohe District (DCL-BH). Based on the above analysis, we divided Hefei city into three parts: BH, DCL-BH, and HF-DCL.

We use RI analysis method to separate the contribution of each explanatory variable to the adjusted $R^{2}$ of the whole model (Johnson and Lebreton, 2004). To make the RI of each variable more easily comparable with others, we standardized the RI values of all explanatory variables. The results of RI analysis, shown in Fig. 10, indicate that for the NDVI prediction model of Lake Chaohu, the GDP growth rate of HF-DCL had the highest $\mathrm{RI}$ in explaining the model $R^{2}$, reaching $39.99 \%$, while the GDP growth rates of $\mathrm{BH}$ and DCL-BH made little difference to the contribution of the model $R^{2}$, indicating that industrial emissions and 
domestic pollutants in the urban area of Hefei promoted the growth of cyanobacteria by working on Lake Chaohu through tributaries. Moreover, the maximum difference was $10.1 \%$ among the three explanatory variables, which shows that the economic growth of the three regions plays an important role in the dynamic variations of cyanobacterial bloom in Lake Chaohu. More precisely, the economic growth of the three regions had little difference in the influence degree of promoting cyanobacteria formation. For the NDVI prediction model in Baohe Lake region, the GDP growth rate in $\mathrm{BH}$ accounted for the largest contribution to explaining the model $R^{2}$, reaching $54.91 \%$, which indicated that Baohe Lake region is significantly influenced by surrounding human activities and the mobility of water is weak, which directly led to the high incidence of cyanobacterial blooms in the Northwest Lake region. Otherwise, the RI values of the other two variables were $22.74 \%$ and $22.35 \%$, and the sum was still less than the RI of the GDP growth rate in $\mathrm{BH}$, which indicates that the GDP growth rate in $\mathrm{BH}$ has a far greater explanative ability for the NDVI than other variables in the Baohe Lake region. Thus, based on the result that the growth rate of $\mathrm{BH}$ was highly interpretable to the NDVI of the Baohe Lake region, we speculate that the NDVI of other lake regions will maintain a consistent correlation with the economic growth of surrounding areas to a large extent.

\section{Discussion}

\subsection{Optimizing the spatial pattern between urban development and surrounding water bodies}

Based on the relationship with the NDVI value in Lake Chaohu, the NDVI value of the Baohe Lake region, the GDP growth rate, and population, urban economic development has an important impact on the neighboring water bodies. The acquisition of such continuous long-term data can effectively capture the variations of cyanobacterial blooms. Our research results can help managers and decision-makers explain and revise their strategies for monitoring cyanobacterial blooms in Lake Chaohu on the basis of economic development and have sustainable economic development significance for optimizing the spatial pattern between the economic development and water bodies in Chaohu Lake Basin and improving the lake water ecological environment. Similarly, the method and results of this study can be extended to other lakes with a frequent occurrence of cyanobacterial blooms, such as Lake Dianchi, Lake Taihu, and Lake Winnipeg. After extracting information on cyanobacteria based on the NDVI obtained from remote sensing data, similar long-term NDVI time series analysis can be carried out at a low cost. The combination of satellite data products and a variety of data to measure the intensity of human activities can further expound the relationship between cyanobacterial variations and economic development.

\subsection{Advantages of the 11-year Landsat time series data}

Cyanobacterial blooms in Lake Chaohu are currently monitored by a water quality observational network of 12 lake monitoring sites. During the period of emergency monitoring, routine monitoring is carried out once a week, and additional monitoring is added once a week from June to November. However, the 
variation that occurs in Lake Chaohu is unpredictable and has a wide range. Therefore, the field sampling method is uncertain for monitoring the short-term and long-term dynamics of cyanobacterial bloom in Lake Chaohu. Moreover, Lake Chaohu is a complex ecosystem as a whole, driven by a variety of factors. Thus, it is necessary to develop a method based on remote sensing technology to monitor the temporal and spatial dynamics of cyanobacterial blooms in Lake Chaohu.

We used Landsat time series data from 2009 to 2019 to establish an 11-year record of cyanobacterial blooms in Lake Chaohu. These data covered the region of Lake Chaohu over four seasons and revealed the dynamic variations of cyanobacterial blooms on a wider spatial scale. Compared with MODIS image data, which are commonly used to monitor spatial and temporal changes of inland and coastal waters, Landsat 7-8 data have higher spatial and temporal resolution and are currently the largest number of images that can be obtained openly, which conforms to the concept of using low-cost remote sensing technology for scientific research. Consequently, the results obtained by applying more Landsat time series data should be more reliable results overall.

\section{Conclusion}

In this study, we used NDVI values derived from Landsat remote sensing data to extract information on cyanobacterial blooms in Lake Chaohu and analyzed the variation trend of NDVI values of cyanobacterial blooms from 2009 to 2019 and their dependence on socioeconomic and meteorological factors. The spatial analysis showed that the annual average NDVI values of Lake Chaohu had obvious interannual variations from 2009 to 2019. The NDVI of the Northwest Lake region was always higher than that of other regions and showed an upward trend from southeast to northwest. The seasonal variations were significant, and the outbreak of cyanobacterial blooms was the most serious in autumn. Statistical analysis results showed that there was a significant relationship between the GDP growth rate of HF, DCL, and $\mathrm{BH}$ and the annual average NDVI of Lake Chaohu and Baohe Lake region. According to the results of $\mathrm{RI}$ analysis, the GDP growth rate of HF-DCL and BH had a higher RI, reaching $39.99 \%$ and $54.91 \%$, respectively. Among them, with the constant narrowing of the economic region, the synchronization of the NDVI value in the Baohe Lake region and the GDP growth rate gradually increased, but the relationship between the NDVI value in Lake Chaohu and the GDP growth rate was exactly opposite. There was also a certain correlation between the population and the NDVI of Lake Chaohu and the Baohe Lake region, but

the correlation was weaker compared with the GDP growth rate. Furthermore, the driving force analysis of meteorological factors, such as temperature, precipitation, sunshine hours, and wind speed indicated that an increase in temperature, sunshine hours, and the decrease of wind speed are conducive to the growth of cyanobacteria in Lake Chaohu.

\section{Declarations}

Acknowledgements This research was supported by the National Natural Science Foundation of China (No. 72071064) and the National Natural Science Funds of China for Innovative Research Groups (No. 71521001). The authors would like to acknowledge the official United States Geological Survey for 
providing Landsat 7-8 images, the Anhui Provincial Bureau of Statistics for providing socioeconomic data, and the China Meteorological Data Sharing Service System for providing meteorological data.

Author contribution All authors contributed to the study conception and design. $\mathrm{XMQ}, \mathrm{WX}$, and $\mathrm{XXH}$ performed the material preparation, data collection and analysis. XMQ wrote the first draft of the manuscript and all authors commented on previous versions of the manuscript. All authors read and approved the final manuscript.

Ethics approval and consent to participate Not applicable.

Consent for publication Not applicable.

Availability of data and materials Data sharing is not applicable to this article as no datasets were generated or analyzed during the current study.

Competing interests The authors declare that they have no competing interests.

\section{References}

1. Cao HY, Han L (2021) Hourly remote sensing monitoring of harmful algal blooms (HABs) in Taihu Lake based on GOCl images. Environ Sci Pollut Res. https://doi.org/10.1007/s11356-021-13318-6.

2. Chander G, Markham BL, Helder DL (2009) Summary of current radiometric calibration coefficients for Landsat MSS, TM, ETM+, and EO-1 ALI sensors. Remote Sens Environ 113:893-903

3. Chen X, Yang XD, Dong XH, Liu EF (2013) Environmental changes in Chaohu Lake (southeast, China) since the mid 20th century: the interactive impacts of nutrients, hydrology and climate. Limnologica, 43:10-17

4. Deering DW (1978) Rangeland reflectance characteristics measured by aircraft and spacecraft sensors. Texas AM University, College Station, Texas

5. Deng JC, Wang YS, Liu X, Hu WP, Zhu JE, Zhu L (2016) Spatial distribution and risk assessment of heavy metals and as pollution in the sediments of a shallow lake. Environ Monit Assess 188:296

6. Du Y, Sun XX (2017) Economic development and environmental quality-a case study of china prefecture-level cities. Environ Prog Sustain 36:1290-1295

7. Guan DB, Hubacek K, Tillotson M, Zhao HY, Liu WD, Liu Z, Liang S (2014) Lifting China's water spell. Environ Sci Tech 48:11048-11056

8. Hu CM, Lee ZP, Ma RH, Yu K, Li DQ, Shang SL (2010) Moderate Resolution Imaging Spectroradiometer (MODIS) observations of cyanobacteria blooms in Taihu Lake, China. J Geophys Res 115:C04002

9. Huang JC, Zhang YJ, Arhonditsis GB, Gao JF, Chen QW, Peng J (2020) The magnitude and drivers of harmful algal blooms in China's lakes and reservoirs: a national-scale characterization. Water Res 181:115902 
10. Huisman J, Codd GA, Paerl HW, Ibelings BW, Verspagen, JMH, Visser PM (2018) Cyanobacterial blooms. Nat Rev Microbiol 16: 471-483

11. Jarchow CJ, Nagler PL, Glenn EP (2017) Greenup and evapotranspiration following the Minute 319 pulse flow to Mexico: an analysis using Landsat 8 Normalized Difference Vegetation Index (NDVI) data. Ecol Eng 106: 776-783

12. Jiang TT, Huo SL, Xi BD, Su J, Hou HB, Yu H, Li X (2014) The influences of land-use changes on the absorbed nitrogen and phosphorus loadings in the drainage basin of Lake Chaohu, China. Environ Earth Sci 71:4165-4176

13. Jiang YJ, He W, Liu WX, Qin N, Ouyang HL, Wang QM, Kong XZ, He QS, Yang C, Yang B, Xu FL (2014) The seasonal and spatial variations of phytoplankton community and their correlation with environmental factors in a large eutrophic Chinese lake (Lake Chaohu). Ecol Indic 40:58-67

14. Johnson JW, Lebreton JM (2004) History and use of relative importance indices in organizational research. Organ Res Methods 7:238-257

15. Kiage LM, Walker ND (2009) Using NDVI from MODIS to monitor duckweed bloom in Lake Maracaibo, Venezuela. Water Resour Manag 23:1125-1135

16. Kutser T (2004) Quantitative detection of chlorophyll in cyanobacterial blooms by satellite remote sensing. Limnol Oceanogr 49:2179-2189

17. Ma JY, Jin SG, Li J, He Y, Shang W (2021) Spatio-temporal variations and driving forces of harmful algal blooms in Chaohu Lake: a multi-source remote sensing approach. Remote Sens 13:427

18. Ma M, Wang X, Veroustraete F, Dong L (2007) Change in area of Ebinur Lake during the 1998-2005 period. Int J Remote Sens 28:5523-5533

19. Ma RH, Yang GS, Duan HT, Jiang JH, Wang SM, Feng XZ, Li AN, Kong FX, Xue B, Wu JL, Li SJ (2010) China's lakes at present: number, area and spatial distribution. Science China Earth Sciences 54:283-289

20. Mu SJ, Li B, Yao J, Yang GS, Wan RR, Xu XB (2020) Monitoring the spatio-temporal dynamics of the wetland vegetation in Poyang Lake by Landsat and MODIS observations. Sci Total Environ 725:138096

21. Nazeer M, Nichol JE, Yung YK (2014) Evaluation of atmospheric correction models and Landsat surface reflectance product in an urban coastal environment. Int J Remote Sens 35:6271-6291

22. Oyama Y, Fukushima T, Matsushita B, Matsuzaki H, Kamiya K, Kobinata H (2015) Monitoring levels of cyanobacterial blooms using the visual cyanobacteria index ( $\mathrm{VCl}$ ) and floating algae index (FAl). Int J Appl Earth Obs Geoinf 38:335-348

23. Paerl HW, Gardner WS, McCarthy MJ, Peierls BL, Wilhelm SW (2014) Algal blooms: noteworthy nitrogen. Science 346:175-175

24. Pahlevan N, Lee ZP, Wei JW, Schaaf CB, Schott JR, Berk A (2014) On-orbit radiometric characterization of OLI (Landsat-8) for applications in aquatic remote sensing. Remote Sens Environ $154: 272-284$ 
25. Palmer SCJ, Kutser T, Hunter PD (2015) Remote sensing of inland waters: challenges, progress and future directions. Remote Sens Environ 157:1-8

26. Qin BQ, Li W, Zhu GW, Zhang YL, Wu TF, Gao G (2015) Cyanobacterial bloom management through integrated monitoring and forecasting in large shallow eutrophic Lake Taihu (China). J Hazard Mater 287:356-363

27. Qin N, He W, Kong XZ, Liu WX, He QS, Yang B, Ouyang HL, Wang QM, Xu FL (2013) Atmospheric partitioning and the air-water exchange of polycyclic aromatic hydrocarbons in a large shallow Chinese lake (Lake Chaohu). Chemosphere 93:1685-1693

28. Schindler DW, Hecky RE, McCullough GK (2012) The rapid eutrophication of Lake Winnipeg: greening under global change. J Gt. Lakes Res 38:6-13

29. Shi K, Li YM, Li L, Lu H (2013) Absorption characteristics of optically complex inland waters: implications for water optical classification. J Geophys Res-biogeo 118:860-874

30. Shi K, Zhang YL, Zhou YQ, Liu XH, Zhu GW, Qin BQ, Gao G (2017) Long-term MODIS observations of cyanobacterial dynamics in Lake Taihu: responses to nutrient enrichment and meteorological factors. Sci Rep 7:40326

31. Stow D, Daeschner S, Hope A, Douglas D, Petersen A, Myneni R, Zhou L, Oechel W (2003) Variability of the seasonally integrated normalized difference vegetation index across the north slope of Alaska in the 1990s. Int J Remote Sens 24:1111-1117

32. Tang J, Shi TZ, Wu XW, Cao HQ, Li XD, Hua RM, Tang F, Yue YD (2015) The occurrence and distribution of antibiotics in Lake Chaohu, China: seasonal variation, potential source and risk assessment. Chemosphere 122:154-161

33. Telesca L, Lasaponara R (2005) Discriminating dynamical patterns in burned and unburned vegetational covers by using SPOT-VGT NDVI data. Geophys Res Lett 32:L21401

34. Vijay R, Pinto SM, Kushwaha VK, Pal S, Nandy T (2016) A multi-temporal analysis for change assessment and estimation of algal bloom in Sambhar Lake, Rajasthan, India. Environ Monit Assess 188. https://doi.org/10.1007/s10661-016-5509-7

35. Vincent RK, Qin XM, McKay RML, Miner J, Czajkowski K, Savino J, Bridgeman T (2004) Phycocyanin detection from LANDSAT TM data for mapping cyanobacterial blooms in Lake Erie. Remote Sens Environ 89:381-392

36. Walls JT, Wyatt KH, Doll JC, Rubenstein EM, Rober AR (2018) Hot and toxic: temperature regulates microcystin release from cyanobacteria. Sci Total Environ 610:786-795

37. Wang MH, Shi W, Tang JW (2011) Water property monitoring and assessment for China's inland Lake Taihu from MODIS-Aqua measurements. Remote Sens Environ 115:841-854

38. Wang XW, Xi BD, Huo SL, Deng L, Pan HW, Xia XF, Zhang JT, Ren YQ, Liu HL (2013) Polybrominated diphenyl ethers occurrence in major inflowing rivers of Lake Chaohu (China): Characteristics, potential sources and inputs to lake. Chemosphere 93:1624-1631

39. Wu PH, Shen HF, Cai N, Zeng C, Wu YL, Wang B, Wang Y (2016) Spatiotemporal analysis of water area annual variations using a Landsat time series: a case study of nine plateau lakes in Yunnan 
province, China. Int J Remote Sens 37:5826-5842

40. Xue K, Zhang YC, Duan HT, Ma RH (2017) Variability of light absorption properties in optically complex inland waters of Lake Chaohu, China. J Gt. Lakes Res 43:17-31

41. Yin HB, Deng JC, Shao SG, Gao F, Gao JF, Fan CX (2011) Distribution characteristics and toxicity assessment of heavy metals in the sediments of Lake Chaohu, China. Environ Monit Assess 179:431-442

42. Zan FY, Huo SL, Xi BD, Li QQ, Liao HQ, Zhang JT (2011) Phosphorus distribution in the sediments of a shallow eutrophic lake, Lake Chaohu, China. Environ Earth Sci 62:1643-1653

43. Zhang YC, Ma RH, Zhang M, Duan HT, Loiselle S, Xu JD (2015) Fourteen-Year record (2000-2013) of the spatial and temporal dynamics of floating algae blooms in Lake Chaohu, observed from time series of MODIS images. Remote Sens 7:10523-10542

44. Zhang YD, Su YL, Liu ZW, Sun KH, Kong LY, Yu JL, Jin M (2018) Sedimentary lipid biomarker record of human-induced environmental change during the past century in Lake Changdang, Lake Taihu basin, Eastern China. Sci Total Environ 613:907-918

45. Zhou LG, Feng XZ, Wang CH, Wang DY (2008) Monitoring cyanobacteria bloom based on MODIS data in Taihu Lake. J Lake Sci 20:203-207

46. Zhu L, Wu CQ, Ya YJ, Zhang YJ (2010) Spatial and temporal distribution variation and meteorological factors analyzing of algal blooms based on $\mathrm{HJ}-1$ satellites in Lake Dianchi, China, 2009. In: IEEE International Geoscience and Remote Sensing Symposium, pp. 2769-2772

\section{Figures}




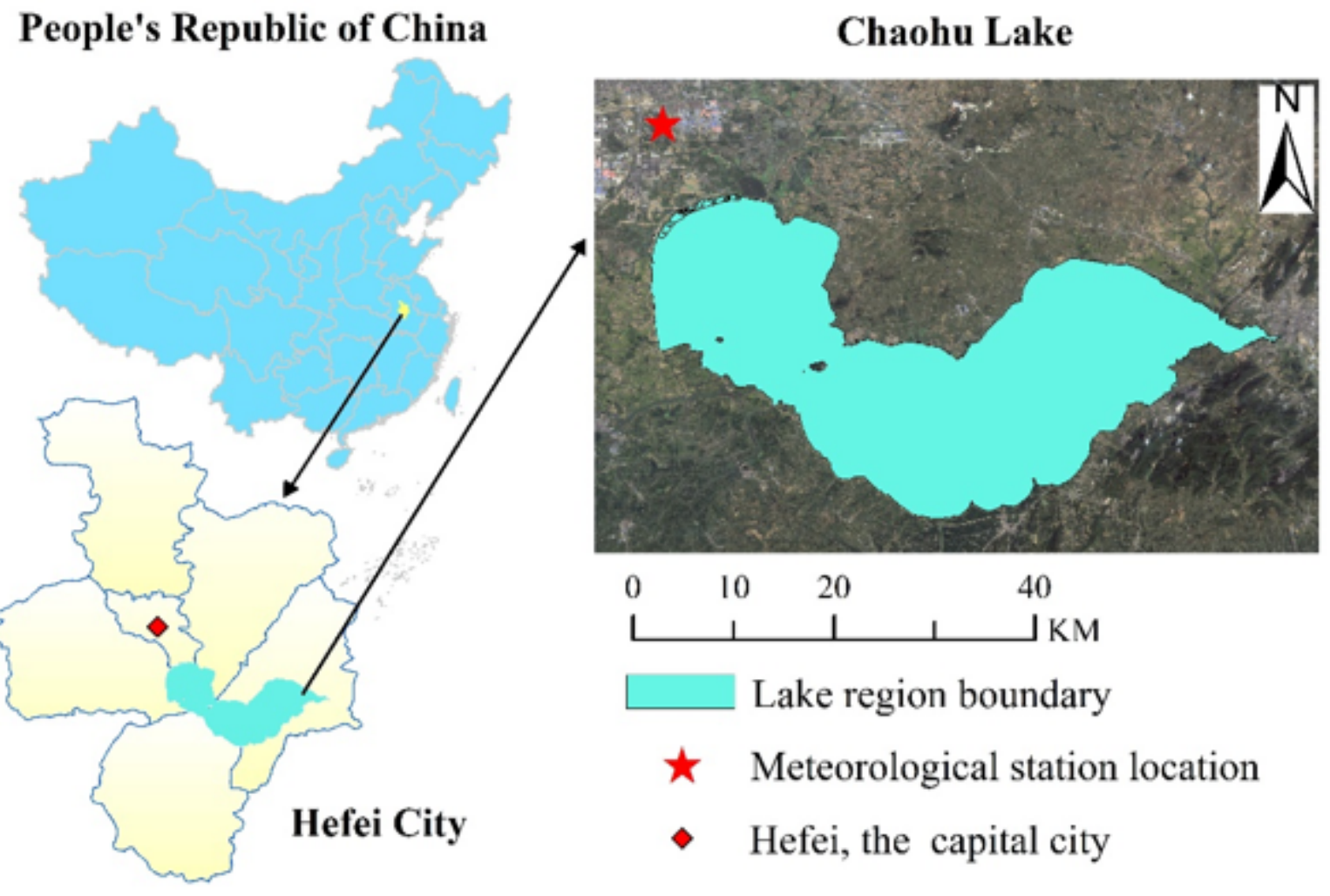

Figure 1

The study area 


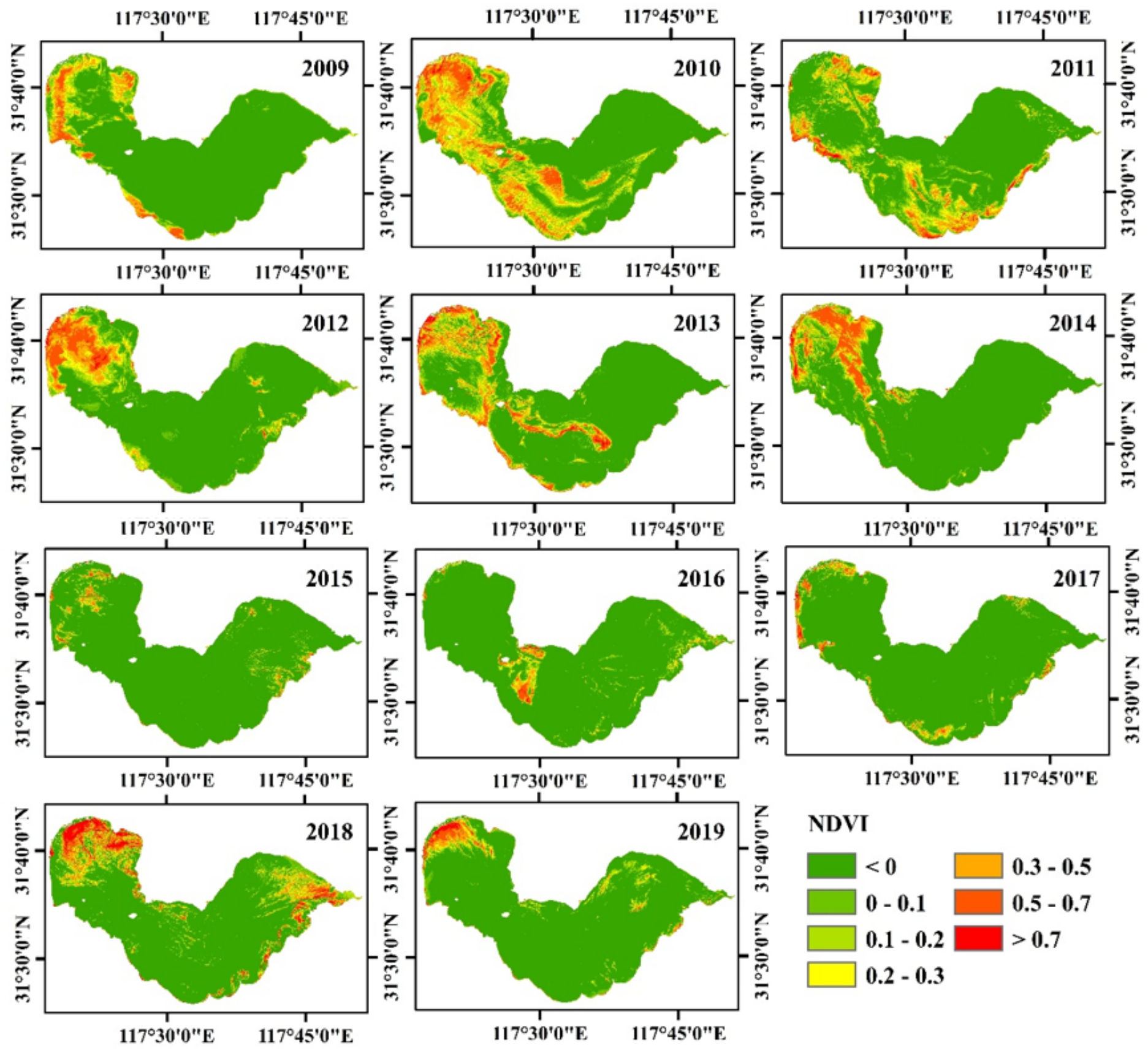

Figure 2

Annual maximum NDVI distributions of Lake Chaohu from 2009 to 2019. The figure was obtained from Landsat data using ArcGIS 10.6 


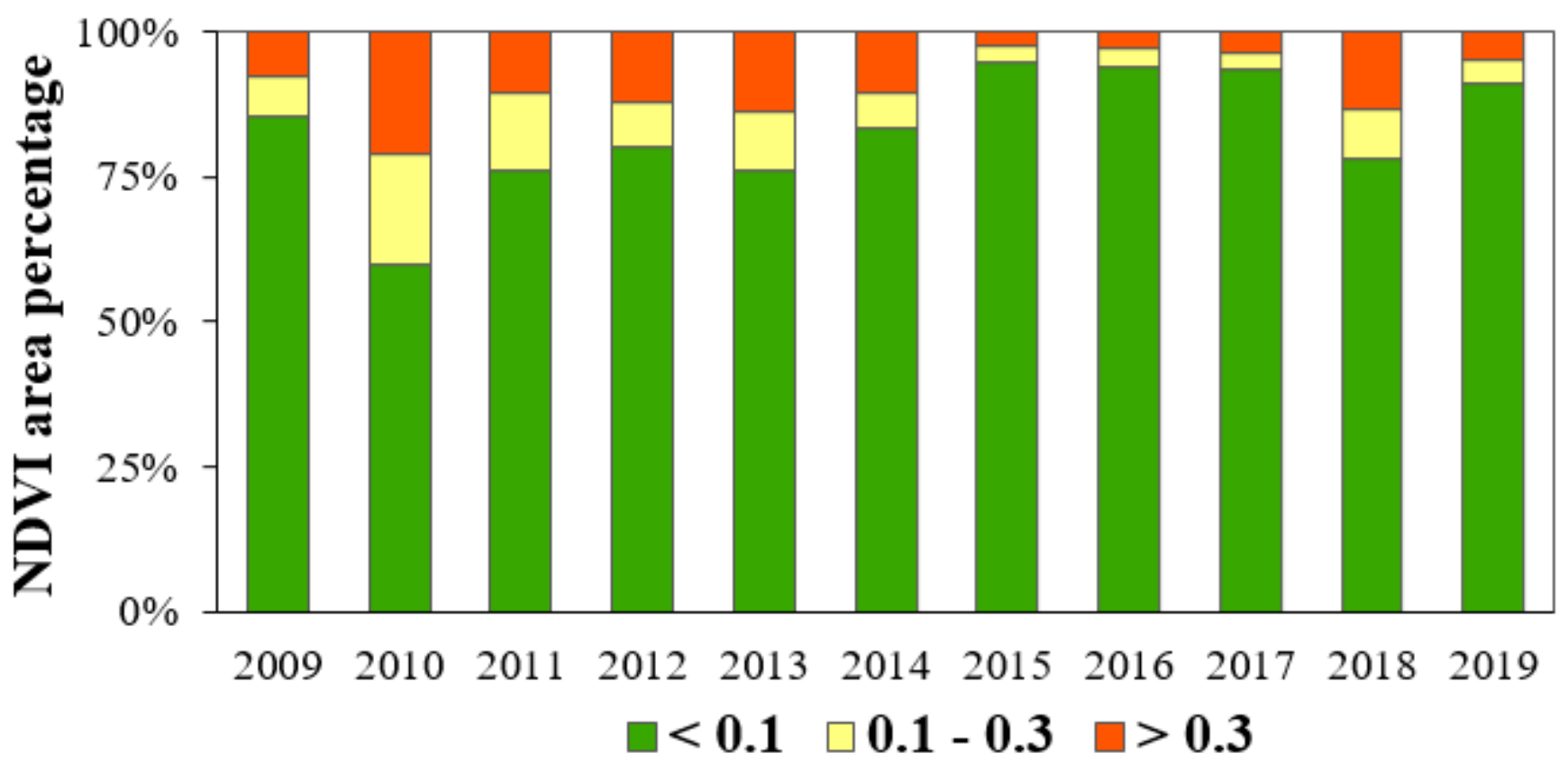

Figure 3

NDVI area percentage at different levels of Lake Chaohu from 2009 to 2019

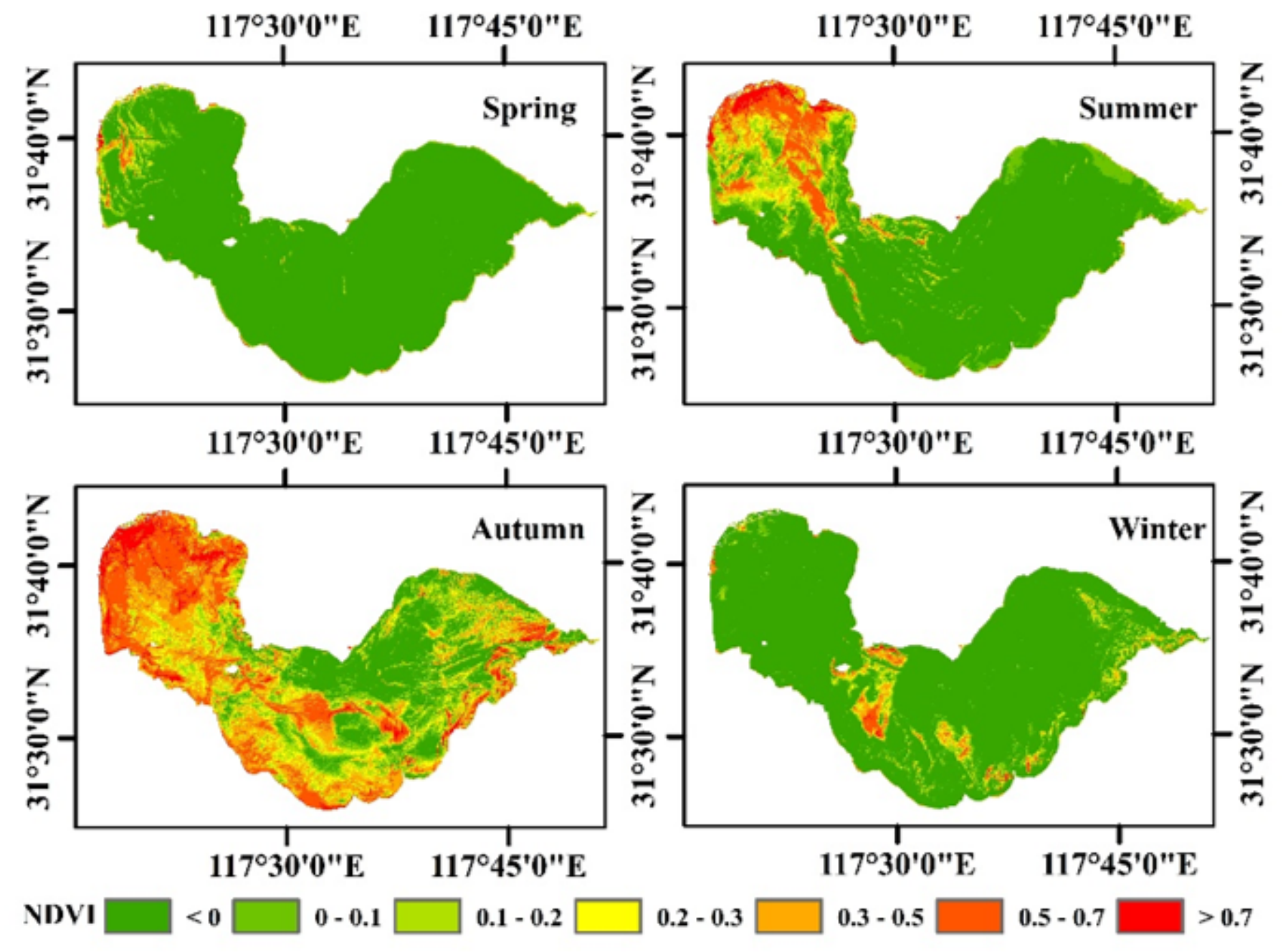


Figure 4

Seasonal maximum NDVI distributions of Lake Chaohu from 2009 to 2019. The figure was obtained from Landsat data using ArcGIS 10.6

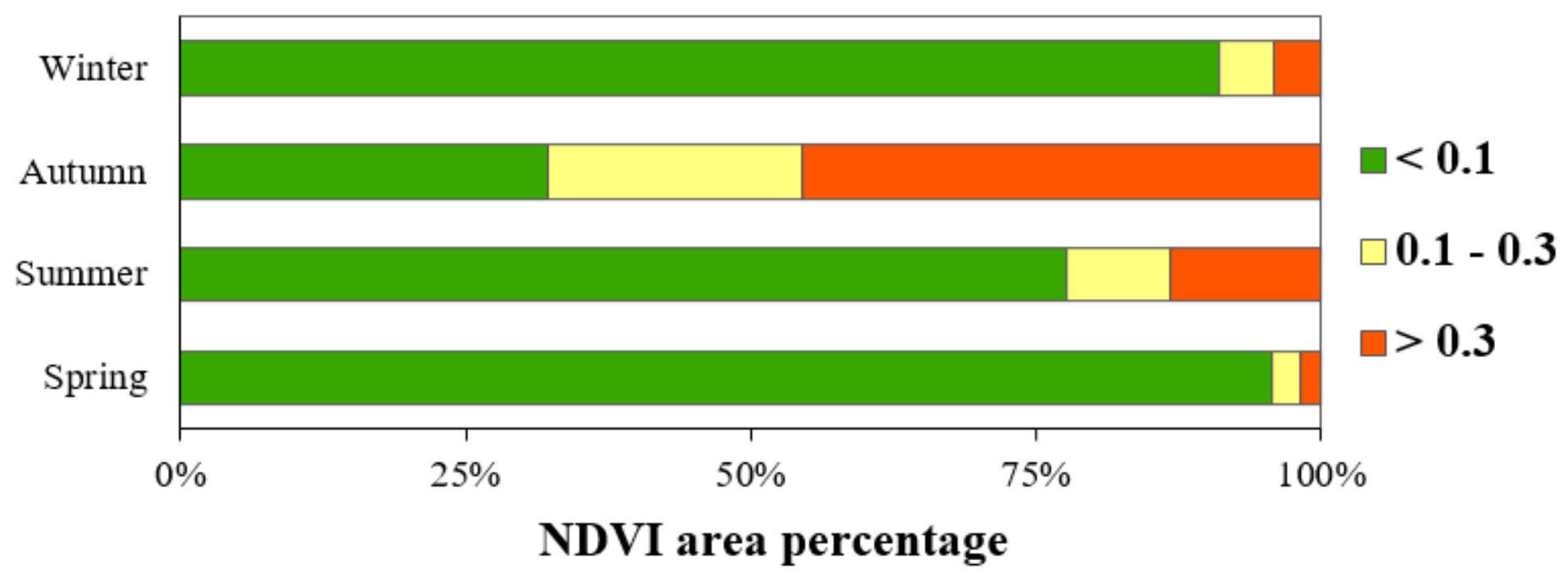

Figure 5

NDVI area percentage at different levels of Lake Chaohu for different seasons
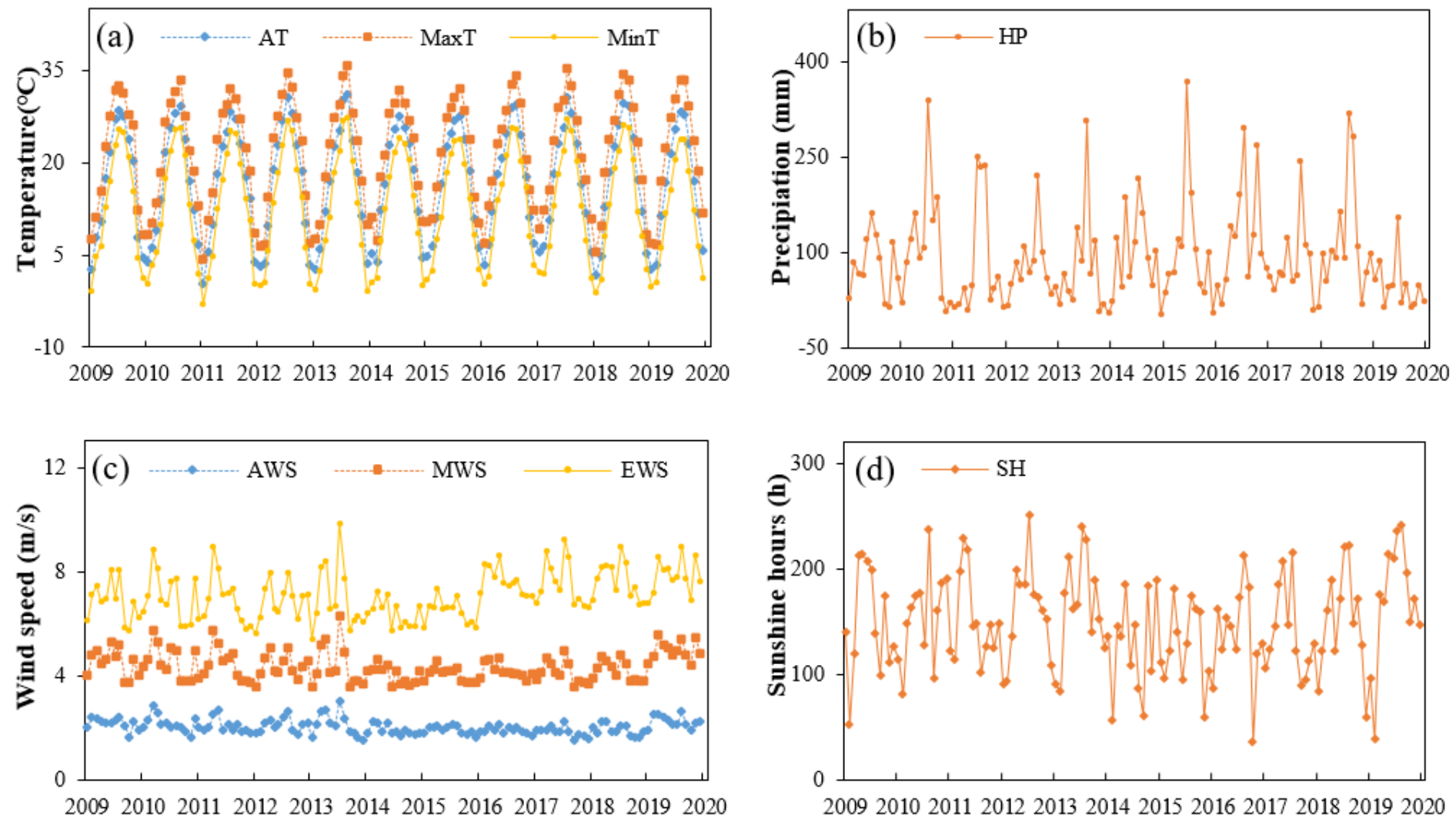

Figure 6 
The monthly dynamics of meteorological factors in Lake Chaohu from 2009 to 2019. The abbreviation of the legends is presented in Table 2
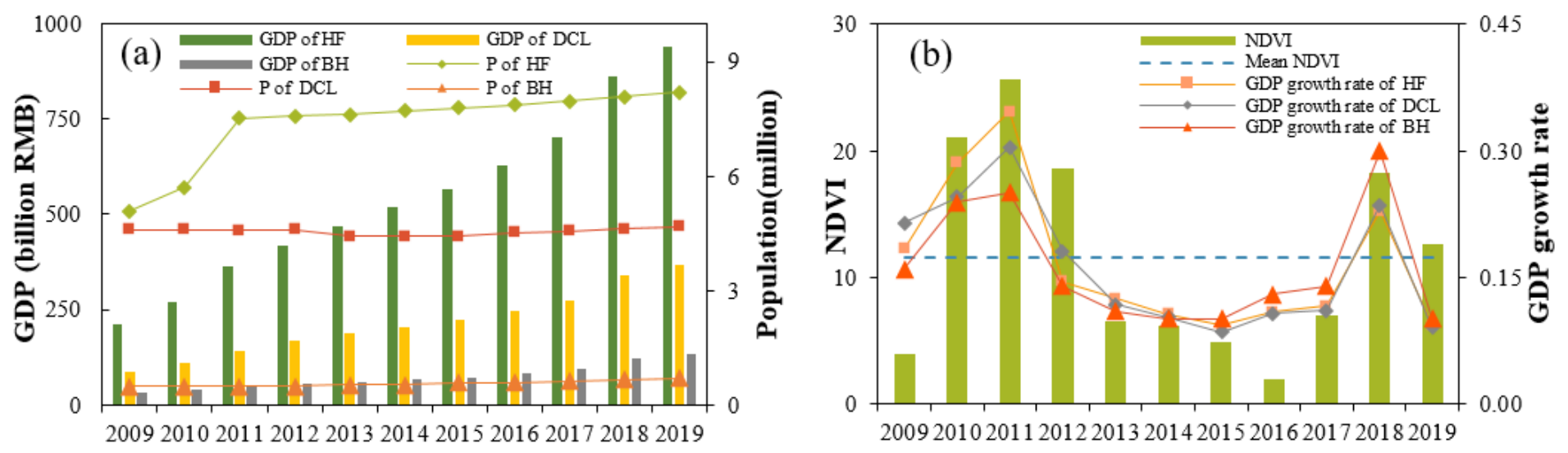

Figure 7

(a) Socioeconomic indices, including GDP, population in HF, DCL and BH, from 2009 to 2019, and (b) Interannual variation in the NDVI and annual GDP growth rate from 2009 to 2019 

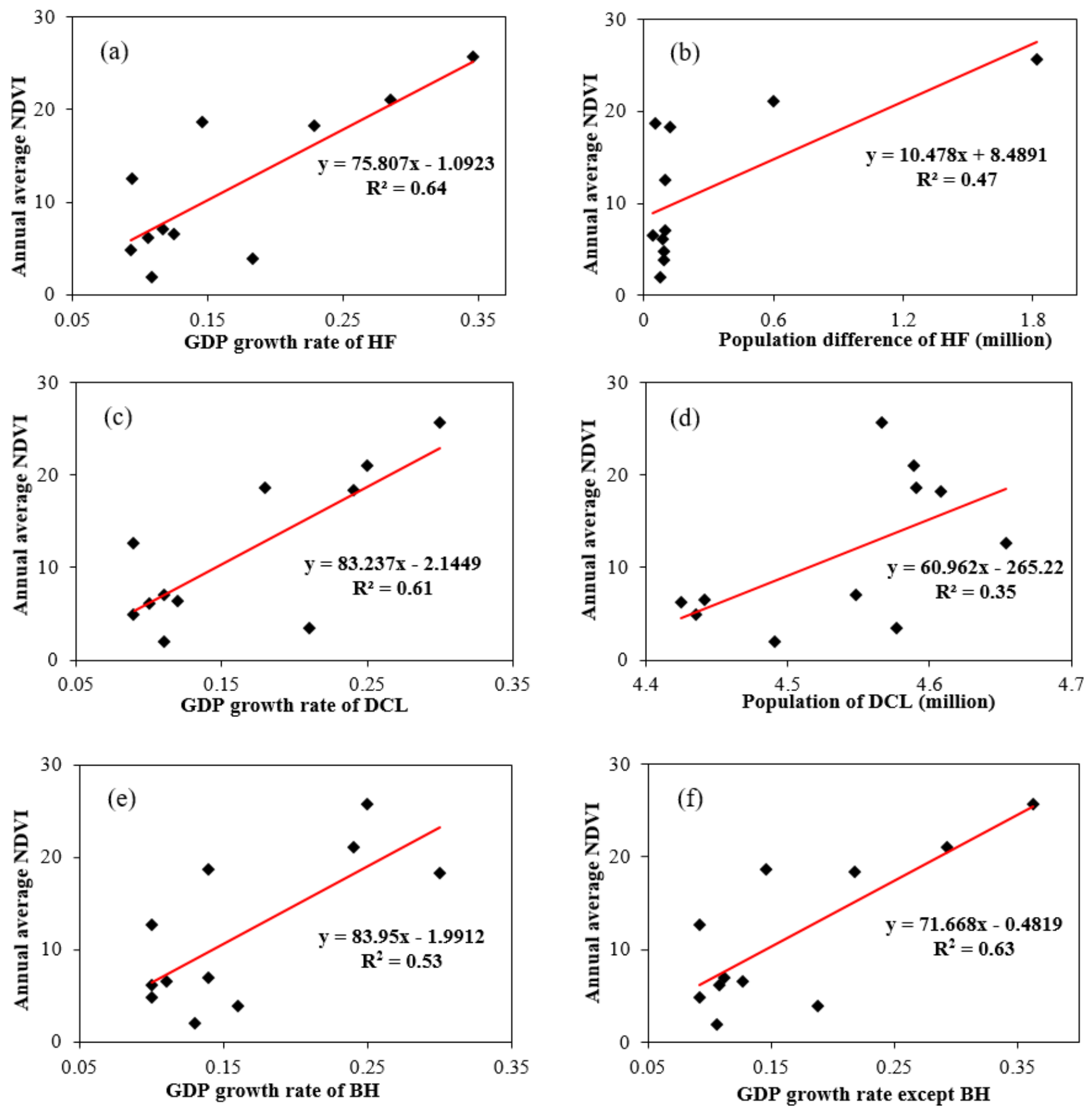

Figure 8

$(a, c, e, f)$ The relationship between annual average NDVI in Lake Cahohu and GDP growth rate, and (b, d) the relationship between annual average NDVI and population 

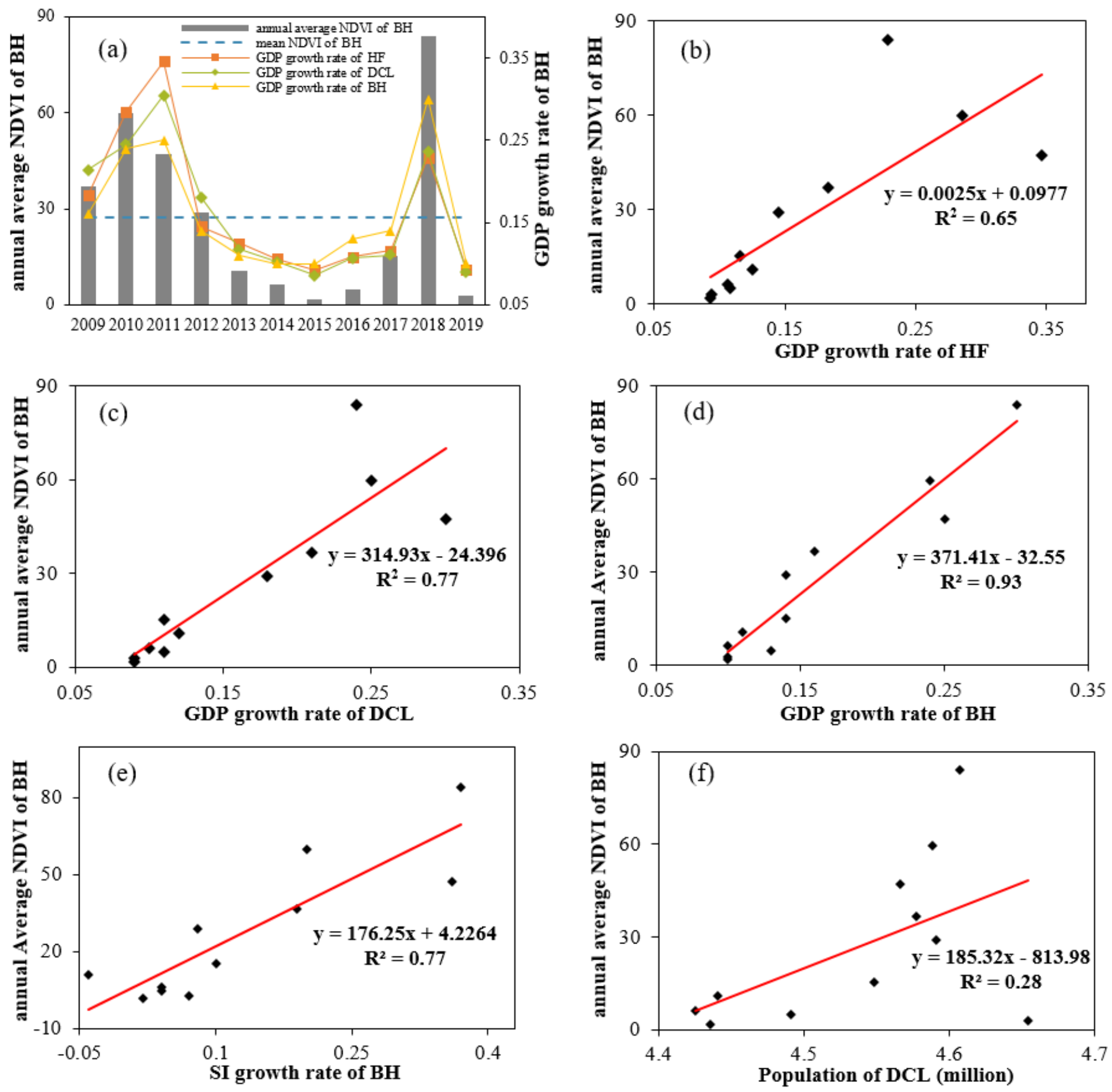

Figure 9

(a) Interannual variation in the NDVI and GDP growth rate in Baohe District from 2009 to 2019, (b, c, d) The relationship between the annual average NDVI of the Baohe Lake region and the GDP growth rate, and $(e, f)$ The relationship between the annual average NDVI of the Baohe Lake region and the growth rate of SI in Baohe District and the population of DCL 
(a)

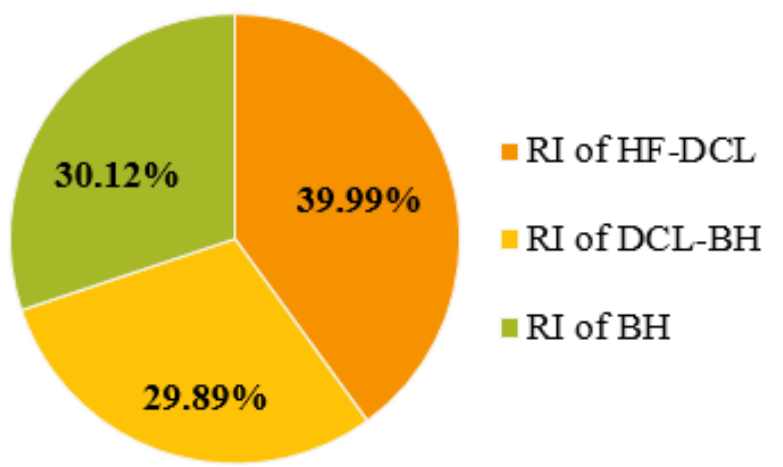

(b)

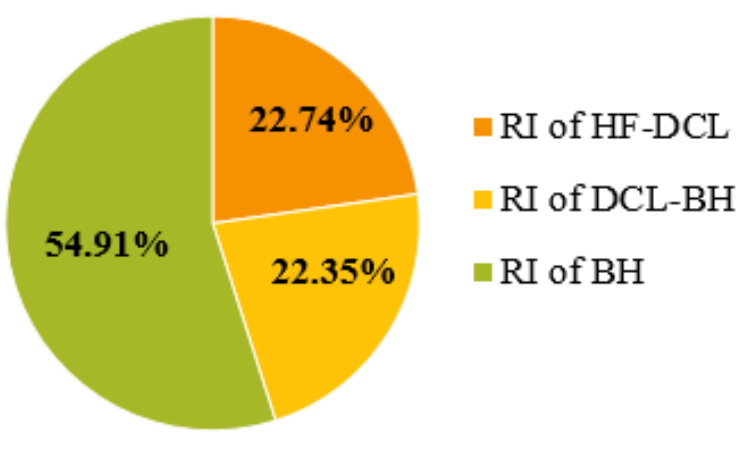

\section{Figure 10}

$(a, b)$ The results of the relative importance analysis of three variables for the NDVI of Lake Chaohu and Baohe Lake region 